\title{
Limited comparability of classifications of levels of neonatal care in UK units
}

\author{
The ECSURF (Economic Evaluation of Surfactant) Collaborative Study Group
}

\begin{abstract}
Aim-To assess whether different classifications of neonatal care or dependency scales are comparable when used in multicentre studies of cost effectiveness. Methods-A survey of classifications was used in a nationally representative group of 57 units in 1990-1, with a retrospective study of 10354 cot days using patient records from a 5\% random sample of 1042 admissions. Local and national classifications were correlated with medical and nursing procedures recorded for up to 26 days after each admission.

Results-Classifications varied substantially. Of the 57 units in our sample, 26 used one of two national classifications, sometimes modified; 17 used the Northern Neonatal Network dependency scale; and the other 14 did not record daily levels of care. In each classification, the highest level was having respiratory support by ventilation or continuous distending pressure through an endotracheal tube, nasal prongs, facemask or negative pressure device. This level of care was consistently comparable between classifications; lower levels were not.

Conclusions-Retrospective comparisons between units with different classifications can only reliably differentiate between days with and without respiratory support. There is a pressing need to develop and validate more appropriate scales for prospective multicentre studies. These should relate activity to costs and outcome. (Arch Dis Child Fetal Neonatal Ed 1998;78:F179-F184)
\end{abstract}

Keywords: classifications of neonatal care; dependency scales; prospective multicentre studies

Assessing the cost effectiveness of neonatal care is increasingly important. However, the work of neonatal units varies from highly invasive support to basic nursing care, and this cannot be ignored when comparing costs within or between units. Many studies in single UK centres ${ }^{1-6}$ have estimated the relative daily costs of different levels of care by detailed observation of individual infants. Estimates of average daily costs per cot were made by dividing up the total costs of each centre in proportion to the total days at each level of care. The overall costs of different groups of infants were then calculated according to their length of stay at each level of care.

This approach has been useful. An observational study showed that the daily costs of caring for very low birthweight infants who died compared with those who survived were six times higher in one unit then another. ${ }^{3}$ Variation in medical policy therefore seems to be a crucial determinant of costs. Other research has combined estimates of daily costs with the results of randomised controlled trials, to calculate the cost effectiveness of confirmed treatments, such as surfactant ${ }^{45}$ or antenatal steroids, ${ }^{4}$ thus enhancing their implementation.

Detailed observation of individual infants by independent observers may be too expensive in large multicentre studies. Fordham and colleagues $^{7}$ therefore estimated the relative daily costs of two broad levels of careintensive and non-intensive-in all neonatal units in Trent using another approach. They apportioned costs entirely from the top down, using routine data. They documented the total costs of each unit and its total cot days at each level of care over a defined period. They then derived the relative daily costs of each level of care across the region from a multiple regression equation. ${ }^{7-9}$ This was an important methodological development, as it showed that variation in total costs between units in a multicentre study could be explained using broad definitions of levels of care. However, this approach requires that each unit uses a comparable classification.

Several classifications of care have been adopted in the UK. In 1984 the then British Paediatric Association (BPA) and the British Association for Perinatal Paediatrics (BAPP) recommended a simple classification to audit workload, denoted as BPA84 in this report. ${ }^{10}$ In 1992 a more comprehensive system, ${ }^{11}$ denoted here as BAPM91, was recommended by the British Association of Perinatal Medicine. In 1993 simple dependency scales were published, supported by detailed observations of nursing activity in the Merseyside regional neonatal intensive care unit and throughout the Northern Region. ${ }^{12-13}$ Many neonatal units have modified one of these classifications or developed their own, and some collect no workload data. At present, purchasers cannot tell whether differences in daily costs between units represent true differences in cost or cost effectiveness, or just differences in definition.

The Medical Research Council funded a three year project from November 1991 for the economic evaluation of surfactant (ECSURF), using data from UK units participating in two international trials of surfactant therapy. ${ }^{14} 15$ The main aim of the ECSURF study ${ }^{16}$ (Mugford et al, unpublished data presented at the 1st annual meeting of the Royal College of Paediatrics and Child Health, 1997) was to cost different levels of intensity of neonatal care in the UK. The relative daily costs of each level of care were estimated by a top down 
Table 1 Level of care definitions

\begin{tabular}{|c|c|c|c|c|}
\hline Original classification & Source of definition & Categories of care & $\begin{array}{l}\text { Neonatal } \\
\text { units }\end{array}$ & $\begin{array}{l}\text { Cot days in the } \\
\text { sample }\end{array}$ \\
\hline \multirow[t]{7}{*}{ BPA 1984} & BPA 1984a (without high dependency category) & IC SC NC & 4 & \\
\hline & BPA $1984 b$ (with high dependency category) & IC HD SC NC & 5 & \\
\hline & Oxford Region SCBU Workload study & IC SC NC & 6 & \\
\hline & SE Thames Region Neonatal Audit & $\begin{array}{l}123 \text { (IC) } \\
45 \text { (SC) } \\
6 \text { (NC) }\end{array}$ & 7 & \\
\hline & \multirow[t]{3}{*}{ West Midlands Region } & A B (IC) & 1 & \\
\hline & & $\mathrm{C} D(\mathrm{SC})$ & & \\
\hline & & $\mathrm{E}(\mathrm{NC})$ & & \\
\hline BAPM 1991 & BAPM 1991a & IC1 IC2 SC NC & 1 & \\
\hline \multirow[t]{2}{*}{ BAPM 1991} & BAPM $1991 \mathrm{~b}$ & $\mathrm{IC}, \mathrm{HD}, \mathrm{SC}$ & 1 & \\
\hline & & & & 4178 \\
\hline \multirow[t]{2}{*}{ NNN } & \multirow[t]{2}{*}{ Northern Region } & A B (HD) & 17 & 2303 \\
\hline & & C D (LD) & & \\
\hline \multicolumn{3}{|c|}{ Total in care level comparison } & 42 & 6481 \\
\hline \multirow{2}{*}{\multicolumn{3}{|c|}{ Other units: excluded from validation study as they lacked routine data on level of care }} & 15 & 3873 \\
\hline & & Total & 57 & 10354 \\
\hline
\end{tabular}

IC intensive care; HD high dependency; LD low dependency; SC special care; NC normal care.

approach, ${ }^{7}$ using multiple regression analysis to relate the total costs of each unit to the proportions of cot days it provided at different levels of care. These estimates were to be combined with the results of the two trials, to measure the incremental short term cost effectiveness of early $v s$ delayed selective surfactant, ${ }^{14}$ and of more $v s$ fewer doses. ${ }^{14}{ }^{15}$ The estimates of the daily costs of different levels of neonatal care derived from ECSURF have also been used for measuring the incremental short term cost effectiveness of ECMO (Roberts et al, unpublished data presented at the First Annual Meeting of the Royal College of Paediatrics and Child Health) and could be applied to any effective neonatal intervention for the UK.

As a first step in the ECSURF project, we assessed how classifications of care used by different units should be adjusted to permit appropriate comparisons of the daily costs of different levels of care.

\section{Methods}

For each of the 61 units participating in the ECSURF study, we collected details of the local classification and the daily care provided to a 5\% sample of babies admitted in the year beginning April 1 1990. In each neonatal unit the records of one infant out of the first 10 admissions were selected using a random number table, then of every subsequent twentieth infant. If the records were missing the next admission to the unit was substituted.

Data were collected from patient records during visits to each unit by one of four research nurses. During their training, methods for extracting data had been standardised between them, using common sets of medical and nursing records. They then compiled a comprehensive list of every medical and nursing procedure used as a criterion in determining any level of care in any of the neonatal units. This involved abstracting from each infant's daily record for up to 26 days after admission all procedures or medications and descriptive variables, including day of death, birthweight, gestational age at birth, and details about transport. The level of care which had been recorded each day by the staff of the unit using its local classification system was also noted for each baby. The highest level of care in every classification was having respiratory support, defined as intermittent positive pressure ventilation (IPPV), intermittent mandatory ventilation (IMV), or continuous positive airway pressure (CPAP) through an endotracheal tube, nasal prongs or face mask, or ventilation or continuous pressure through a negative pressure device. Because all of these babies would be classified similarly in different

Table 2 Examples of criteria included in all or only some definitions

\begin{tabular}{|c|c|c|}
\hline Care level & Included in all definitions & Included in some but not all definitions \\
\hline Highest level of intensive care & Receiving any form of respiratory support & $\begin{array}{l}\text { Dying baby } \\
\text { Day of death } \\
\text { Day of transport (various definitions) } \\
\text { Receiving parenteral (or total parenteral) } \\
\quad \text { nutrition (various definitions) } \\
\text { Oxygen level above } 40 \% \text { (or } 60 \% \text { ) } \\
\text { Having significant circulatory support } \\
\text { Weighing less than } 1000 \mathrm{~g}\end{array}$ \\
\hline $\begin{array}{l}\text { Second highest level, } \\
\text { or subdivision of highest level } \\
\text { (high dependency care) }\end{array}$ & & $\begin{array}{l}\text { Pre- or postoperative care (various } \\
\text { definitions) } \\
\text { Unstable cardiorespiratory condition } \\
\text { (various definitions) }\end{array}$ \\
\hline Second to lowest level (special care) & $\begin{array}{l}\text { Receiving additional oxygen, if not ventilated } \\
\text { Receiving IV electrolyte or dextrose fluids }\end{array}$ & $\begin{array}{l}\text { Receiving regular physiotherapy, dressings, } \\
\text { etc. } \\
\text { Being nursed in an incubator } \\
\text { With tracheostomy } \\
\text { Radiological examination or other imaging }\end{array}$ \\
\hline Lowest level of neonatal unit care & & $\begin{array}{l}\text { Fully breast/bottle fed baby weighing over } \\
1750 \mathrm{~g} \text { being observed (with no criteria } \\
\text { for higher level) }\end{array}$ \\
\hline
\end{tabular}


Table 3 Occurrence of criteria as percentage of baby days

\begin{tabular}{|c|c|c|c|c|}
\hline & All units & $B P A$ units & NNN units & Others \\
\hline Number of neonatal units & 57 & 25 & 17 & 15 \\
\hline Number of baby days observed & 10354 & 4178 & 2303 & 3873 \\
\hline $\begin{array}{l}\text { Having respiratory support days } \\
(\%)\end{array}$ & $\begin{array}{r}1535 \\
(14.8)\end{array}$ & $\begin{array}{l}781 \\
(18.7)\end{array}$ & $\begin{array}{l}244 \\
(10.6)\end{array}$ & $\begin{array}{l}510 \\
(13.2)\end{array}$ \\
\hline No respiratory support days & 8819 & 3397 & 2059 & 3363 \\
\hline$(\%)$ & $(85.2)$ & (81.3) & (89.4) & $(86.8)$ \\
\hline \multicolumn{5}{|l|}{ Per cent of non ventilated days with: } \\
\hline Current weight $<1000 \mathrm{~g}$ & 2.8 & 4.1 & 1.5 & 2.3 \\
\hline Current weight $1000 \mathrm{~g}-1500 \mathrm{~g}$ & 13.1 & 15.3 & 9.1 & 13.2 \\
\hline Current weight $>1500 \mathrm{~g}$ and $<1750 \mathrm{~g}$ & 10.3 & 12.4 & 9.5 & 8.7 \\
\hline In an incubator & 44.2 & 47.9 & 36.0 & 45.5 \\
\hline During $24 \mathrm{~h}$ following withdrawal of artificial ventilation & 1.6 & 2.3 & 0.6 & 1.6 \\
\hline Additional oxygen: $>60 \%$ & 0.6 & 0.9 & 0.4 & 0.4 \\
\hline Additional oxygen: $40 \%-60 \%$ & 2.2 & 3.4 & 1.6 & 1.4 \\
\hline Addtional oxygen: $<40 \%$ & 9.5 & 12.1 & 8.2 & 7.6 \\
\hline Unstable cardiorespiratory disease & 0.8 & 0.3 & 0.3 & 1.5 \\
\hline Recurrent apnoea & 3.6 & 5.7 & 0.1 & 3.5 \\
\hline $\begin{array}{l}\text { Constant monitoring of respiration, heart rate or with } \\
\text { transcutaneous monitors }\end{array}$ & 36.8 & 41.6 & 25.3 & 39.0 \\
\hline Receiving amino acids IV & 6.7 & 8.8 & 0.8 & 8.2 \\
\hline Receiving dextrose/electrolyte fluid IV & 21.0 & 23.0 & 17.1 & 21.4 \\
\hline Having any bottle/breast feeds & 67.6 & 60.4 & 75.5 & 70.0 \\
\hline Having any tube feeds & 60.9 & 64.9 & 56.5 & 59.6 \\
\hline Having significant circulatory support & 0.2 & 0.1 & 0.4 & 0.1 \\
\hline Having arterial catheter inserted & 0.5 & 0.9 & 0 & 0.4 \\
\hline Arterial line in situ & 2.3 & 3.6 & 0.8 & 1.9 \\
\hline Receiving peritoneal dialysis & 0 & 0 & 0 & 0 \\
\hline Receiving exchange transfusion & 0.2 & 0.2 & 0.1 & 0.1 \\
\hline Phototherapy & 11.3 & 9.9 & 9.6 & 13.6 \\
\hline Any other major medical procdures & 0.6 & 0.7 & 0.5 & 0.5 \\
\hline During the first $24 \mathrm{~h}$ before major surgery & 0.2 & 0.2 & 0.2 & 0.2 \\
\hline During the first $24 \mathrm{~h}$ following major surgery & 0.2 & 0.2 & 0.1 & 0.3 \\
\hline Up to $48 \mathrm{~h}$ following major surgery & 0.2 & 0.2 & 0.1 & 0.2 \\
\hline $\mathrm{Up}$ to $48 \mathrm{~h}$ following minor surgery & 0.2 & 0.3 & 0 & 0.1 \\
\hline $\begin{array}{l}\text { More than } 48 \mathrm{~h} \text { postoperative and requiring complex } \\
\text { nursing procedures }\end{array}$ & 0 & 0 & 0 & 0 \\
\hline Baby with chest drain & 0.4 & 0.8 & 0 & 0.1 \\
\hline Baby with urethral drain & 0.3 & 0.1 & 0 & 0.7 \\
\hline During the first two weeks with a tracheostomy & 0 & 0 & 0 & 0 \\
\hline With tracheostomy after the first two weeks & 0 & 0 & 0 & 0 \\
\hline Having convulsions & 0.7 & 0.9 & 0.4 & 0.6 \\
\hline Fit in last $24 \mathrm{~h}$ & 0.6 & 0.9 & 0.2 & 0.7 \\
\hline Antibiotics IV or oral & 22.9 & 26.4 & 17.2 & 22.9 \\
\hline Barrier nursing & 0.6 & 0.4 & 0.7 & 0.8 \\
\hline Radiological examination or other imaging & 9.1 & 11.5 & 5.4 & 9.0 \\
\hline \multicolumn{5}{|l|}{$\begin{array}{l}\text { Having regular physiotherapy, dressings, care of } \\
\text { oro/nasopharyngeal tubes }\end{array}$} \\
\hline Receiving special monitoring & 22.9 & 28.5 & 14.2 & 22.6 \\
\hline Receiving constant supervision & 1.8 & 2.3 & 1.4 & 1.5 \\
\hline Completely breast/bottle fed $>1750 \mathrm{~g}$ being observed & 13.9 & 6.5 & 33.0 & 9.8 \\
\hline Transported in from another unit & 1.0 & 1.4 & 0.5 & 1.0 \\
\hline Transported out to another unit & 1.4 & 1.4 & 1.3 & 1.4 \\
\hline Transported by this unit's medical and nurse team & 0.5 & 0.7 & 0.1 & 0.6 \\
\hline Transported by another unit's medical and nurse team & 0.6 & 0.9 & 0.3 & 0.4 \\
\hline Transported by this unit's trained neonatal nurse & 0.9 & 1.1 & 0.8 & 0.7 \\
\hline Transported by another unit's trained neonatal nurse & 1.1 & 1.3 & 0.6 & 1.1 \\
\hline Day of death & 0.1 & 0.1 & 0 & 0.1 \\
\hline Terminal care except on day of death & 0.1 & 0.1 & 0.1 & 0 \\
\hline
\end{tabular}

units, no other procedures were recorded on days when respiratory support was given.

Neonatal units were divided into three groups according to written definitions of their local classifications of care:

(i) units using a local classification modified from the BPA84 or BAPM91 classifications; (ii) units using the Northern Neonatal Network dependency scale, a system derived from detailed observations of nursing and medical work; and

(iii) other units, with no daily record of level of care.

For units in groups (i) and (ii) the data collected were entered in a computer algorithm to reclassify each cot day according to the original versions of two national classifications, BPA84 and BAPM91. The distribution of cot days at each level of care using the local classification was compared with the distribution of cot days using the two national standards. We used a statistical method de- scribed by Fleiss, ${ }^{17}$ which estimates the degree of inter-rater agreement, beyond what might be expected by chance alone, expressed as the $\kappa$ statistic. We postulated that $\kappa$ would exceed 0.9 , where a value of 1 indicates perfect correspondence between classification systems. As this method can only compare classifications with identical numbers of categories, we amalgamated local classifications with four or more categories in two ways to produce only three levels of care. First, we merged the two highest categories below respiratory support in each local classification as intensive care (local a). Second, we kept the highest category below respiratory support in each local classification separate and merged the lower categories (local b). In each comparison the proportion of cot days at each of the three levels constructed using the local classification was correlated with the corresponding proportion of cot days using the original BPA84 and BAPM91 classifications. 
Table 4 Comparison of local classification with BPA84 and BAPM91 national standards

\begin{tabular}{|c|c|c|c|c|c|c|c|}
\hline Group of units & Classification ${ }^{\star}$ & $\begin{array}{l}\text { Respiratory } \\
\text { support }\end{array}$ & $\begin{array}{l}\text { Intensive care - } \\
\text { no respiratory } \\
\text { support }\end{array}$ & $\begin{array}{l}\text { Special } \\
\text { care }\end{array}$ & $\begin{array}{l}\text { Nursery } \\
\text { care }\end{array}$ & $\begin{array}{l}\text { Total number of } \\
\text { days with level of } \\
\text { care data }\end{array}$ & $\begin{array}{l}\text { Missing level } \\
\text { of care data }\end{array}$ \\
\hline \multicolumn{8}{|l|}{$\begin{array}{l}\text { Number of days at } \\
\text { each level of care: }\end{array}$} \\
\hline \multirow[t]{4}{*}{$\mathrm{BPA} / \mathrm{BAPM}(\mathrm{n}=25)$} & Local a & 664 & 552 & 1546 & 640 & 3402 & 776 \\
\hline & Local b & 664 & 284 & 1814 & 640 & 3402 & \\
\hline & BPA84 & 664 & 765 & 1572 & 401 & 3402 & \\
\hline & BAPM91 & 664 & 461 & 1864 & 413 & 3402 & \\
\hline \multirow[t]{4}{*}{$\mathrm{NNN}(\mathrm{n}=17)$} & Local a & 218 & 172 & 1169 & 718 & 2277 & 26 \\
\hline & Local b & 218 & 14 & 1327 & 718 & 2277 & \\
\hline & BPA84 & 218 & 382 & 1148 & 529 & 2277 & \\
\hline & BAPM91 & 218 & 120 & 1400 & 539 & 2277 & \\
\hline \multirow[t]{4}{*}{ All units $(n=42)$} & Local a & 882 & 724 & 2715 & 1358 & 5679 & 802 \\
\hline & Local b & 882 & 315 & 3124 & 1358 & 5679 & \\
\hline & BPA84 & 882 & 1147 & 2720 & 930 & 5679 & \\
\hline & BAPM91 & 882 & 581 & 3264 & 952 & 5679 & \\
\hline \multicolumn{8}{|l|}{ Per cent of days } \\
\hline \multirow[t]{4}{*}{$\mathrm{BPA} / \mathrm{BAPM}(\mathrm{n}=25)$} & Local a & 20 & 16 & 45 & 19 & 100 & \\
\hline & Local b & 20 & 8 & 53 & 19 & 100 & \\
\hline & BPA84 & 20 & 22 & 46 & 12 & 100 & \\
\hline & BAPM91 & 20 & 14 & 55 & 12 & 100 & \\
\hline \multirow[t]{4}{*}{$\mathrm{NNN}(\mathrm{n}=17)$} & Local a & 10 & 8 & 51 & 32 & 100 & \\
\hline & Local b & 10 & 0 & 58 & 32 & 100 & \\
\hline & BPA84 & 10 & 17 & 50 & 23 & 100 & \\
\hline & BAPM91 & 10 & 5 & 61 & 24 & 100 & \\
\hline \multirow[t]{4}{*}{ All units $(n=42)$} & Local a & 16 & 13 & 48 & 24 & 100 & \\
\hline & Local b & 16 & 6 & 55 & 24 & 100 & \\
\hline & BPA84 & 16 & 20 & 48 & 16 & 100 & \\
\hline & BAPM91 & 16 & 10 & 57 & 17 & 100 & \\
\hline
\end{tabular}

Note on classifications compared:

Local a Intensive $=$ the next two most intensive levels in the local classification were merged

Local $\mathrm{b}$ Intensive $=$ the next most intensive level in the local classification was preserved; two intermediate or lower categories were merged

$\left.\begin{array}{l}\text { BPA84 } \\ \text { BAPM91 }\end{array}\right\}$ re-classification by researchers of cot days using BPA/BAPM national classifications. ${ }^{10} 11$

Finally, we used methods for probit and ordered probit regression analysis which do not require the same number of categories when comparing each classification. ${ }^{18}$ Probit analysis can estimate the relation between a categorical outcome, such as the level of care a baby was assigned in any given classification, and the specific procedures conducted on that day. This approach was used to identify criteria associated with particular levels of care which were shared between groups of neonatal units using different classifications. The aim was to show how consistently different classifications allocated babies to similar levels of care.

The data were processed and checked using double data entry, and were subsequently analysed using SAS (Version 6.08), SPSS for Windows (Version 6.1.1) and the LIMDEP econometric package (Version 6.0).

\section{Results}

Of over 100 UK neonatal units taking part in either of the two surfactant trials, ${ }^{14} 1561$ were invited to take part in ECSURF because of

Table 5 Kappa statistics and Spearman rank correlation coefficients for comparisons of days of care with different classifications

\begin{tabular}{|c|c|c|c|}
\hline & Kappa & $\begin{array}{l}\text { Spearman } \\
\text { correlation } \\
\text { coefficient }\end{array}$ & $p$ Value \\
\hline \multicolumn{4}{|l|}{ BPA group: } \\
\hline Local a vs BPA84 & 0.27672 & 0.48 & $<.001$ \\
\hline Local b vs BPA84 & 0.24760 & 0.48 & $<.001$ \\
\hline Local a vs BAPM91 & 0.40175 & 0.55 & $<.001$ \\
\hline Local b vs BAPM91 & 0.38789 & 0.53 & $<.001$ \\
\hline \multicolumn{4}{|l|}{ NNN group: } \\
\hline Local a vs BPA84 & 0.59273 & 0.74 & $<.001$ \\
\hline Local b vs BPA84 & 0.46646 & 0.69 & $<.001$ \\
\hline Local a vs BAPM91 & 0.64452 & 0.71 & $<.001$ \\
\hline Local b vs BAPM91 & 0.65494 & 0.70 & $<.001$ \\
\hline
\end{tabular}

reasonable proximity to the study coordinators. Four units were unable to provide data about annual costs of care, so $57 \mathrm{UK}$ neonatal units were surveyed. Of these, 26 units used variants of the BPA84 and BAPM91 classifications and 17 used the Northern Region nursing dependency scale which classified care into four groups, consisting of two levels of dependency, high and low, with two subdivisions of each level. The other 14 did not record daily levels of care (table 1).

We compiled a list of 51 criteria used to classify care in different levels. Table 2 shows that only one of these criteria was shared by all classifications. This was having respiratory support, which always constituted intensive care. There were no consistent criteria for normal care, which includes well babies being prepared for home.

We recorded details of care given to 1042 infants for 10354 cot days in the 57 neonatal units. The birthweight profile of these infants was $54(5 \%)$ less than $1000 \mathrm{~g} ; 103(10 \%)$ between 1000 and $1499 \mathrm{~g} ; 317(30 \%)$ between 1500 and $2499 \mathrm{~g}$; and 563 (54\%) $2500 \mathrm{~g}$ or more. Table 3 shows how frequently each of the 51 criteria occurred in our sample of cot days. Only 20 cot days of care (less than 0.2 per cent) included dialysis or exchange transfusion. Although care before and after surgery denoted high dependency and intensive care in some classifications, it accounted for less than $50 \mathrm{cot}$ days in over 10000 .

Forty four per cent of cot days included incubator care, 24 per cent included antibiotic treatment, but less than 0.5 per cent were with barrier nursing. Thirty-seven per cent of cot days included constant monitoring but less 
NURSING WORKLOAD LOG

- Please put this sheet on a clipboard by the nursing station

- Please complete every column of this log at noon and midnight without fail

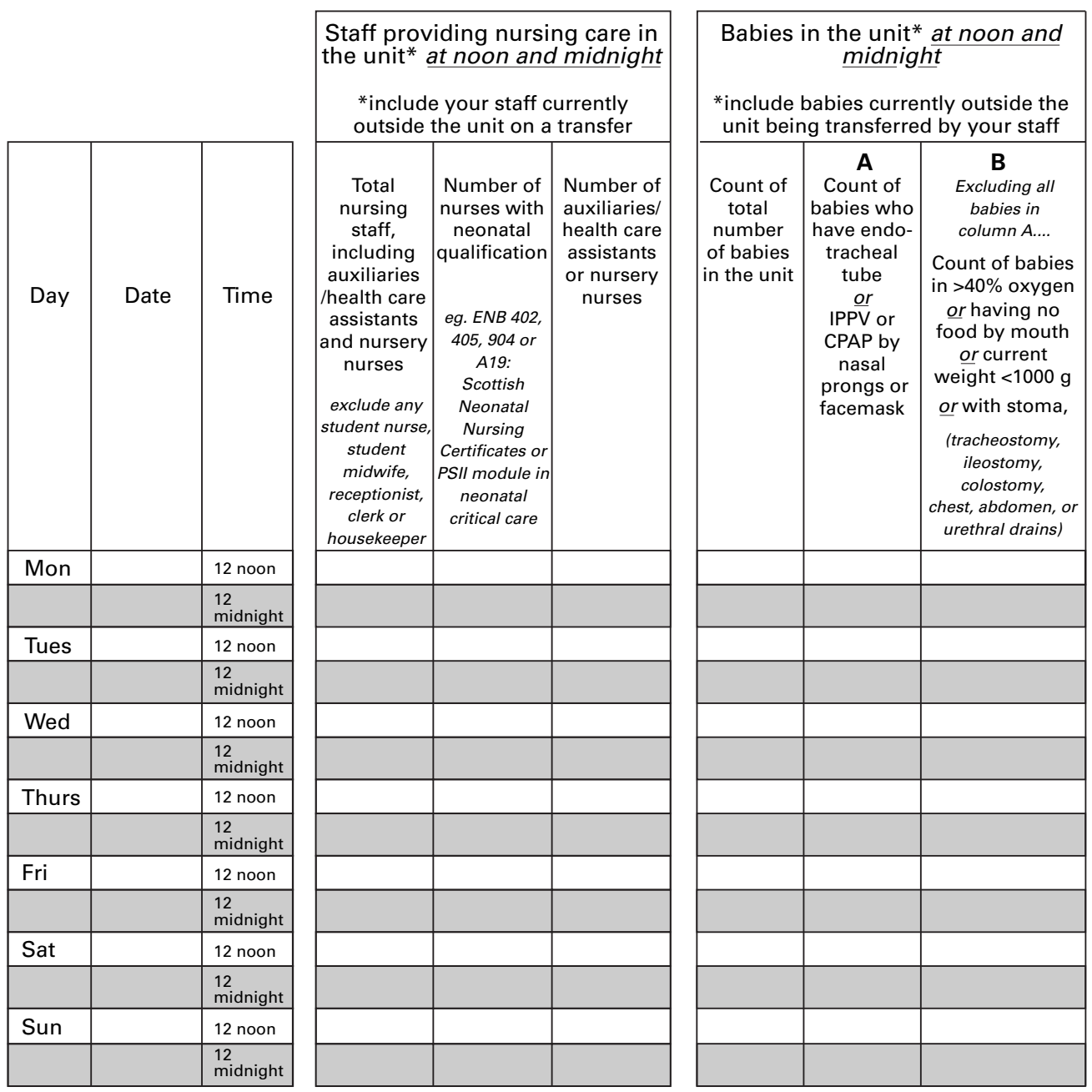

Figure 1 A practical dependency scale, based on previous work, ${ }^{13}$ used in the UK Neonatal Staffing Study. ${ }^{27}$

than 1 per cent included any record of unstable cardio-respiratory disease. Only on about 3 per cent of non-ventilated days could the baby be classified as having had recurrent apnoea requiring at least five stimulations in 24 hours. Nearly 14 per cent of non-ventilated baby days in our sample were for wholly breast or bottle fed babies weighing over $1750 \mathrm{~g}$.

Table 4 shows our estimates of the proportions of days at different levels of care according to the BPA84 and BAPM91 classifications, among neonatal units using local classifications $a$ and $b$. Using the BPA84 classification, we overpredicted the numbers of non-ventilated intensive care days, and found similar numbers of special care days in both groups. Using the BPA91 definition, non-ventilated intensive days closely matched the intensive care and high dependency categories merged in local classification a. In both groups of neonatal units we estimated a lower proportion of nursery care than was actually recorded locally.

There was a significant correspondence between the predicted workload based on different classifications (table 5). However, in every case, the pre-specified hypothesis that the classifications would be highly concordant was rejected, as the underlying $\kappa$ statistic never exceeded 0.9 .

According to probit analysis, no single criterion was a consistent predictor for levels of care other than respiratory support. It was impossible to derive a common model that would predict levels of care in different groups of neonatal units.

\section{Discussion}

Although local and national classifications uniformly identified respiratory support as the highest level of care, they were otherwise not closely comparable, which confirms previous findings. ${ }^{13}$ In retrospective comparisons between units using different classifications it seems appropriate to differentiate only between days with and without respiratory support.

There are several potential problems with the statistical data and methods we have used. Firstly, we may have missed certain procedures because they were not in the notes or were 
overlooked during data collection. This would have exaggerated the influence of items which were recorded. Secondly, neonatal units might deviate from their adopted classification to record higher categories of care to justify already stretched staffing levels. ${ }^{19}$ However, we found the opposite: local classifications overestimated the numbers of days at the lowest level of care. Third, our 5 per cent sample of admissions may have created selection bias. Censoring the data after the 26th day and substituting the next admission when the records of randomly selected infants were missing may have caused infants with long stays and chronic problems to be under-represented. However, as these infants usually received long term respiratory support this bias is unlikely to alter the main conclusion that this level of care was consistent between classifications.

Routinely recording daily occupancy using detailed classifications of levels of care has an established role in allocating staff and documenting trends within units. However, in multicentre studies there are strong grounds for developing a simple common denominator, to minimise interobserver variation and the expense of coordinating comprehensive data collection. ${ }^{13}$ An alternative would be to use diagnostic related groups for neonatal care, as suggested by the Clinical Standards Advisory Group. ${ }^{20}$ However, this approach has been criticised when applied in the USA for reimbursement of costs. ${ }^{21}$

Clearly, there is a pressing need to develop appropriate classifications of care or dependency scales for prospective multicentre studies and these should be carefully validated before they are widely accepted. How should this be done?

The most rigorous validation of a dependency scale would require studies which relate its levels of care to costs, activity, and outcome. In the original top down costing study by Fordham and colleagues, ${ }^{7}$ the broad categories of intensive $v s$ non intensive care accounted for $76 \%$ of the variation in costs between neonatal units in Trent. Williams et $a l^{12}$ and the Northern Neonatal Network ${ }^{13}$ reported simple, practical dependency scales which were supported by detailed, prospective analyses of nursing activity. These suggested that, on average, ventilated infants who were stable required only slightly more nursing time than highly dependent infants who were not ventilated. Following these studies, the British Association of Perinatal Medicine has recommended that a nurse should not be responsible for more than two infants receiving neonatal intensive care or more than four infants receiving special care, ${ }^{22}$ and has acknowledged that its previous more stringent standards ${ }^{11}$ for levels of nursing staff lacked empirical evidence and were rarely met. ${ }^{22}$ Another important test of the validity of a classification of care would be to use it to show whether outcomes deteriorate when workload is excessive. This would allow us in turn to test the validity of current recommendations for minimum safe levels of staffing. ${ }^{22}$

Figure 1 illustrates an example of a practical dependency scale consistent with previously validated analyses of nursing activity, ${ }^{12}{ }^{13}$ which will be used in a random sample of units in the
UK Neonatal Staffing Study. ${ }^{23}$ This twice daily $\log$ of unit workload is designed to provide a common currency using uniform definitions across about 50 units in the prospective phase of that study, which aims to relate patient volume, levels of staffing provision, and workload to costs and outcome.

We conclude that simple and uniform scales for comparative studies of the costs of neonatal care are needed. Without this, research on the costs and cost effectiveness of neonatal care in the NHS will continue to be more expensive and less reliable than it should be.

We thank Susan Fritz, Mary McCulloch, Beth McDonagh, Hazel Ashurst, Lisa Wood and Lindsay Bramley for data collection and processing. We thank all of the neonatal units who participated in this study and colleagues at the National Perinatal Epidemiology Unit and members of the UK Neonatal Staffing Study for their comments.

We are grateful to Douglas Richardson for advice with the analysis. Miranda Mugford, Sarah Howard, and Alistair Dunn were funded by the Department of Health. The Project for the Economic Evaluation of Surfactant was funded by the Medical Research Council, which supported Morag Zelisko.

1 Newns B, Drummond MF, Durbin GM, Culley P. Costs and outcomes in a regional neonatal intensive care unit. Arch Dis Child 1984;59:1064-7.

2 Ryan S, Sics A, Congdon P. Costs of neonatal care. Arch Dis Child 1988;63: 303-6.

3 Sandhu B, Stevenson RC, Cooke RWI, Pharoah POD. Costs of neonatal care for very low birthweight infants. Lancet 1986;i:600-3.

4 Mugford M, Piercy J, Chalmers I. Cost implications of different approaches to the prevention of respiratory distress ferent approaches to the prevention of respir
syndrome. Arch Dis Child 1991;66:757-4.

5 Tubman TRJ, Halliday HL, Normand C. Cost of surfactant replacement treatment for severe neonatal respiratory distress syndrome: a randomised controlled trial. BMJ 1990;301:842-5.

6 Mugford $M$. The cost of neonatal care: reviewing the evidence. Social and Preventive Medicine 1995;40:361-8.

7 Fordham R, Field DJ, Hodges S, et al. Cost of neonatal care across a health authority. If Public Health Med 1992;14:127-30.

8 O'Neill C, Largey A. Issues in cost function specification for neonatal care: the Fordham case. 7 Public Health Med 1997;19:50-4.

9 Tarnow-Mordi WO, Tucker J, McCabe C, et al. Issues in cost function specification for neonatal care: an inter-disciplinary perspective. 7 Public Health Med 1997;19:479-80.

10 British Paediatric Association and British Association for Perinatal Pediatrics. Categories of babies requiring neonatal care. Arch Dis Child 1985;60:599-600.

11 British Association of Perinatal Medicine and Neonatal Nurses Association. Report of a working group of the British Association of Perinatal Medicine and Neonatal Nurses Association on categories of babies requiring neonurses Association on categories of babies

12 Williams S, Whelan A, Weindling AM, Cooke RWI. Nursing staff requirements for neonatal intensive care. Arch Dis Child 1993;68:534-8.

3 Northern Neonatal Network. Measuring neonatal nursing workload. Arch Dis Child 1993;68:539-43.

14 The OSIRIS Collaborative Group. Early versus delayed synthetic surfactant - the judgement of OSIRIS. Lancet 1992;340:1363-9.

15 Halliday HL, Tarnow-Mordi WO, Corcoran JD, Patterson CC (on behalf of the European Collaborative Multicentre Study Group). Multicentre randomised trial comparing respiratory distress syndrome (the Curosurf 4 trial). Arch Dis Child 1993;69:276-80.

16 Tarnow-Mordi WO, Halliday HL, Hey E, Malek M, Normand C, Mugford $M$. The economics of neonatal surNormand C, Mugford M. The economics of
factant therapy. MRC News 1992; 57:16-17.

17 Fleiss JL. Statistical methods for rates and proportions. 2nd edn. New York: John Wiley, 1981.

18 Greene WH. Econometric analysis. London: MacmIllan Publishing Company, 1991

19 Redshaw ME, Harris A, Ingram JC. The neonatal unit as a working environment: a survey of neonatal nursing. London: HMSO, 1996.

20 Clinical Standards Advisory Group. Neonatal intensive care. Access to and availability of specialist services. London: HMSO, 1993.

21 Resnick MB, Aruet M, Carter RL, et al. Prospective pricing system for tertiary neonatal intensive care. Pediatrics 1986;78:567-73.

22 British Association of Perinatal Medicine. Standards for hospitals providing neonatal intensive care. London: BAPM, 1996.

23 Tarnow-Mordi WO, Tucker JS, McCabe CJ, Nicolson P, Tarnow-Mordi WO, Tucker JS, McCabe CJ, Nicolson P,
Parry GJ, on behalf of the UK Neonatal Staffing Study Collaborative Group. The UK Neonatal Staffing Study: a prospective evaluation of neonatal intensive care in the prospective evaluation of neonatal
UK. Semin Neonatol 1997;2:171-9. 